Perspective

\title{
Target Tau, not Amyloid, to Prevent and Treat Alzheimer's Disease
}

\author{
Margaret M Esiri ${ }^{*}$
}

Nuffield Department of Clinical Neurosciences, University of Oxford, Neuropathology Department, West Wing, John Radcliffe Hospital, Oxford OX3 9DU, UK; E-Mail: Margaret.esiri@ndcn.ox.ac.uk

* Correspondence: Margaret M Esiri; E-Mail: Margaret.esiri@ndcn.ox.ac.uk

Academic Editor: Michael Fossel

Special Issue: Treatment of Dementia

\section{OBM Geriatrics}

2020, volume 4, issue 1

doi:10.21926/obm.geriatr.2001103
Received: November 17, 2019

Accepted: January 22, 2020

Published: February 04, 2020

\begin{abstract}
In this article I wish to put the case for a change of emphasis in the approach to finding a prevention/treatment for Alzheimer's disease from a focus on beta amyloid to one on tau. In particular, I make the case for aiming to prevent the spread of abnormal tau from the medial temporal lobe to widespread areas of association cortex that are anatomically linked to this critical region. I pose an analogy with cardiovascular disease in which the initiating pathology, lipid streaks, are left untreated until they are so extensive as to provoke secondary pathology, the treatment of which, in many cases, controls the effects of disease. In Alzheimer's disease beta amyloid, if it is the initiating pathology, represents the equivalent of lipid streaks in this analogy and tau the secondary pathology that needs to be curtailed to control the disease.
\end{abstract}

\section{Keywords}

Tau; beta amyloid; Alzheimer's disease; cardiovascular disease

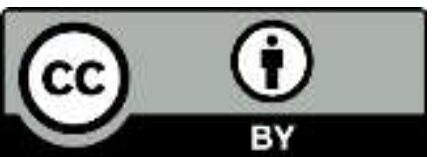

(C) 2020 by the author. This is an open access article distributed under the conditions of the Creative Commons by Attribution License, which permits unrestricted use, distribution, and reproduction in any medium or format, provided the original work is correctly cited. 


\section{Introduction}

I want to reinforce the case here for a switch of focus from beta amyloid to tau when considering the immense problem of how to limit the prevalence of dementia due to Alzheimer's disease $(A D)$ in the world's ageing human populations.

I can understand the logic of targeting beta amyloid, which has been the main approach (largely unsuccessful, see [1]) so far to trying to control AD. Beta amyloid is the principal component of $A D$ plaques and it is the molecule that has been focussed upon as the initial molecule that needs to be eradicated in a complex pathological cascade that results in most cases of dementia. This may be the logical implication of genetically determined AD caused by point mutations that increase the production of beta amyloid or alter the balance of the longer beta amyloid 1-42 over the shorter 140 version of the peptide [2]. But such cases only account for less than $5 \%$ of cases of $A D$, or cases of $A D$ developing in Down Syndrome. There is less evidence that over-production of beta amyloid accounts for the far more numerous cases of sporadic, late-onset AD (LOAD). These may relate more to poor elimination of beta amyloid plaques or their predecessor molecules [3].

However, be that as it may, my main argument for switching attention from amyloid to tau to prevent or treat early $A D$ is different. It is based on the very strong evidence that the severity of cognitive decline in $A D$ is related to how widespread neurofibrillary tangle(NFT) formation is in the brain. In contrast, the amount of amyloid in the brain is barely related to the severity of dementia in AD. This has been known at least since the early 1980s when Gordon Wilcock and I published a paper on the subject [4] (indeed since the work of Tomlinson et al, [5]), yet it seems to have been relatively ignored by those attempting to develop a treatment for AD. Numerous more recent studies have confirmed this observation [6-12].

\section{Cardiovascular Disease Analogy}

A telling analogy can perhaps be drawn by considering the manner in which cardiovascular disease (CVD) has been substantially reduced in developed countries in recent years. CVD due to atheroma deposits in major arteries is, like $A D$, a form of pathology that develops slowly, over decades. It commences with the formation of lipid streaks beneath the endothelial layer of the affected arteries in adolescence or the third decade of life $[13,14]$. It only causes major problems when it becomes so abundant as to limit the flow of blood through the narrowed lumen of vessels or when secondary developments such as thrombosis arise. In both CVD and AD inflammatory processes have important roles to play. I suggest that in some ways the asymptomatic lipid streak phase of CVD is comparable to the asymptomatic early phase of AD in which beta amyloid plaques can be detected on imaging, but NFT are absent or scarce and confined to the transentorhinal region where they first appear in the forebrain. With CVD great improvements in outcome have come not from limiting the formation of lipid streaks (although we are all encouraged to eat a diet that does not encourage their formation) but by reducing the risk of such streaks becoming large and provoking secondary effects. When considering $A D$, instead of focusing on eliminating beta amyloid plaques, positive translational outcomes could, in my opinion, come from discovering how to confine NFT formation to the transentorhinal region, where it (or the processes with which it is associated) may make it difficult to remember names, but doesn't cause the calamity that is fully developed AD. 


\section{Restricting NFT Spread}

We need to understand what factors, in undemented elderly people, limit the spread of NFT along neuroanatomical pathways that connect this part of the brain to more widespread regions of cerebral cortex. It may be no coincidence that the medial temporal lobe which contains the transentorhinal cortex and the hippocampus are regions that display and retain plasticity throughout life [15]. This plasticity is thought to be needed to enable new memories to be formed and it is the failure of this function early in $A D$ that leads to impaired memory for recent events. As NFT formation spreads outside this region, as AD pathology progresses and cognition becomes progressively impaired, it generally does so in a stereotyped fashion reflecting the closeness of neurons, in terms of neuroanatomical connections, to this region [16-18]. In recent years this spread has been found to resemble in some respects the spread of abnormal prion protein to and within the brain in the spongiform encephalopathies $[19,20]$. Therefore, we may learn as much as or more that is of value in containing $A D$ from studies of the spread of prion protein and the similarities that aggregated tau 'spreading' shows to this, rather than from studies of beta amyloid in isolation.

Transcellular spread of tau protein has been the subject of several recent experimental studies but it remains unknown how this process takes place in the human brain. Experimental studies have shown elaboration of tau filaments after injection into wild type mice of tau derived from the P301S tau transgenic murine model of $A D$ or from human $A D$ brain extracts [21-23]. One study reported that it was a soluble, phosphorylated, high molecular weight form of tau that can be taken up, axonally transported and transferred to synaptically connected neurons in vitro [24]. In vitro studies and animal models of $A D$ have demonstrated that a number of factors can influence tau phosphorylation, usually a prerequisite for formation of tau fibrils $[25,26]$. These include cellular prion protein and beta amyloid [27, 28], ischemia [29], ApoE4 [30], microglia and, in particular, molecules expressed by microglia, including CCR5 [31] and TNF alpha [32, 33], neurotrophin receptor p75 [34], other post translational modifications to tau apart from phosphorylation [35] and an insulin resistance environment [36].

Apart from increasing understanding of the triggering factors that initiate the formation of aggregated tau, the pathological form that spreads through the brain, we need to increase understanding of the manner in which seeds of aggregated, phosphorylated tau can be propagated from one cell to another [37]. Because of the precision with which the spread of tau in $A D$ corresponds to neuroanatomical connectivity it is widely supposed that abnormal tau spreads across synapses to post-synaptic cells in which it acts as a template for the creation of further aggregated tau (Figure 1) [16-18]. However, there may be other cellular players in this propagation process. Microglial cells have, in particular, come under scrutiny in this context [38-41]. If they have a role to play it may explain why many of the genetic risk factors for late onset $A D$ are related to molecules expressed by cells involved with the immune system. 


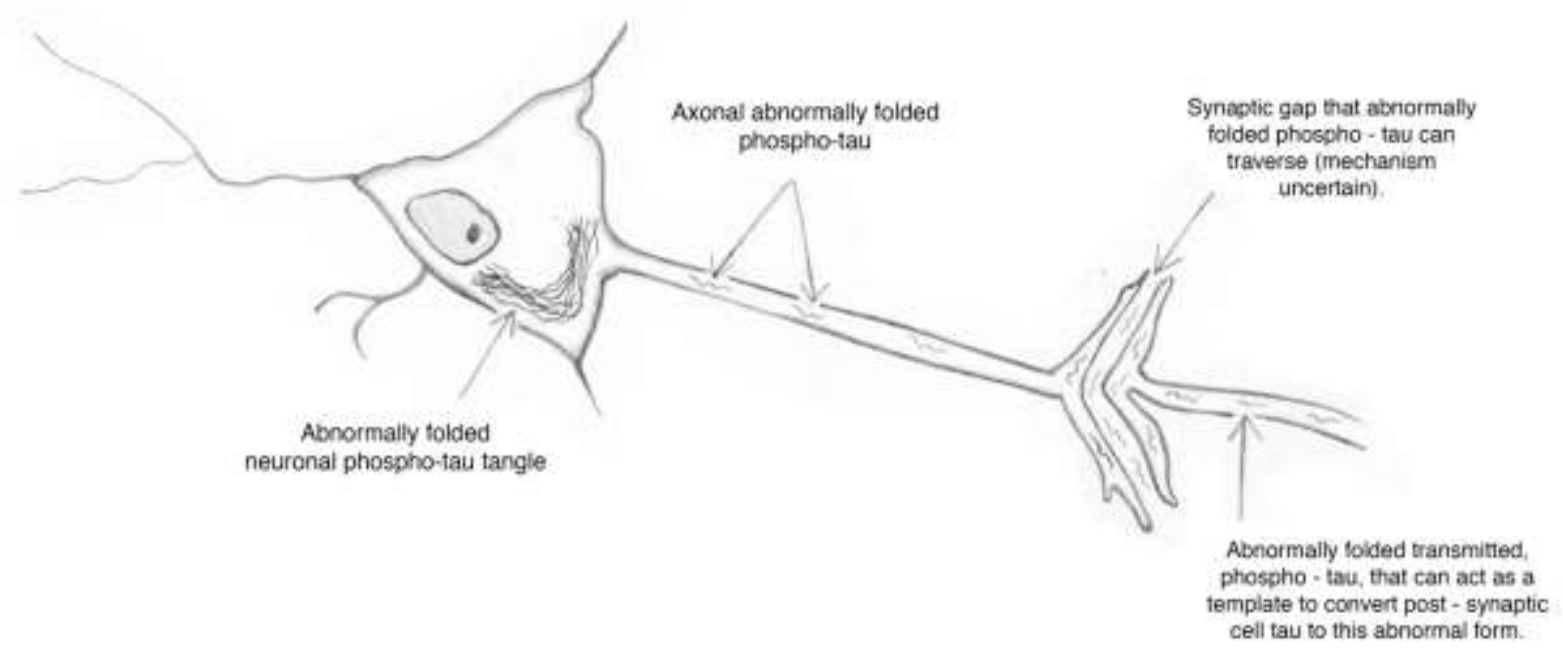

Figure 1 Diagrammatic representation of postulated spread of abnormally folded phospho-tau in Alzheimer's disease.

There are some who consider that the recently developed view of prion-like spreading of tau in $A D$ is not so different from the older hypothesis that tau pathology spreads by 'seeded polymerisation' [42]. This view is allied with the idea that the pattern of spread of AD pathology is related to selective vulnerability of certain groups of neurons. These two hypotheses - of tau spreading and neuronal selective vulnerability - are not mutually exclusive and both may have value. Certainly the initial triggering of tau misfolding in entorhinal cortex would seem to demonstrate a selective vulnerability of the distinctive pre-alpha cells of layer one of this region of cortex. Tau seeded polymerisation or prion-like spread applies much more convincingly to the subsequent spread of tau pathology.

There is a difference between demonstrating build-up of aggregated proteins in axonally linked neurons and showing that this causes damage to the affected neurons. In human AD the fact that those brain nuclei in which NFT are found also suffer neuronal loss in the disease implicates processes related to NFT formation, if not the NFT themselves, in cell cytotoxicity [43]. But the molecular mechanisms of such cytotoxicity are not at present understood. One factor likely to be involved is failure of assembly of microtubules which hyperphosphorylation of tau causes [4446].Such mechanisms will need to be further delineated to give the best chance of using tau as a target to prevent or treat AD. On the other hand, if the underlying processes that enable many old people to restrict NFT formation to the entorhinal cortex and interconnected hippocampal neurons could be uncovered that may provide the opportunity to control this disease.

\section{Therapies Now Targeting Tau}

It is encouraging to see that potential therapies targeting tau are now beginning to make their appearance [47], though only one has so far reached a Phase 3 trial [48]. Anti-tau antibodies are prominent among these approaches. Some are aimed at preventing tau phosphorylation or lowering the expression of tau. Some antibodies have been shown to reduce the propagation of aggregated tau between nerve cells in vitro, those antibodies directed at N-terminal and middomain moieties of tau being more effective than one directed against the C-terminal portion of the molecule [49]. Some in vivo studies in mouse models of AD have shown reduced pathology 
and improved cognition with anti-tau immunotherapy [50,51]. These promising results have been reported despite some initial scepticism about whether antibodies could effectively target intracellular molecules like those in NFT. Success may be down to aggregated tau passing into the extracellular space in vivo, en route to another cell. There is also evidence that antibodies to tau can gain entry to neuronal cytoplasm [52]. New developments may allow better targeting of intracellular tau by a modified form of immunotherapy using intrabodies [53].

\section{Epidemiological Evidence of a Recent Reduction in Prevalence of Dementia}

Some grounds for optimism when considering the problem of $A D$ come from the recent evidence in developed countries of a reduction in the prevalence of dementia in the last few years [54]. Although the cause of this welcome finding is not entirely clear it is likely to be related to the manner in which some risk factors for the development of dementia have been mitigated to some extent in the last 20 years or so. This has partly come about because these risk factors are shared with CVD and have been tackled to bring down the high prevalence of CVD. Thus, better detection and control of blood pressure and elevated cholesterol levels in blood have been achieved, and encouragement of more exercise and sleep promoted. This has had a knock-on effect of reducing dementia risk. Much more needs to be done along these lines but measures that can be taken in middle life to reduce the risk of late onset $A D$ are now better recognised. However, exactly how these CVD risk factors promote $A D$ remains little understood and merits further research.

\section{Concluding Remarks}

Finally, I am not advocating the abandonment of research on amyloid beta but for a change in the balance of emphasis to make spread of tau pathology a focus of more importance than hitherto. Beta amyloid is one of the factors that affects the spread of tau pathology in experimental models [27] and this aspect of its influence should repay further investigation so it needs to continue to be studied. In humans amyloid beta is required for aggregated tau to extend into the neocortex $[7,55,56]$. Furthermore, amyloid plaques in an experimental mouse model of $A D$ were reduced in the subiculum by an immunisation regime directed the tau amino terminal region [57]. Thus, the two major forms of microscopic pathology in AD are intimately connected. In my opinion, it is plausible that amyloid plaques are generated at the axonal terminations of neurons bearing NFT. This scenario is suggested by the frequent finding of a row of plaques in the dendritic field of hippocampal dentate granule cells, the destination of axonal terminations of neurons vulnerable to NFT formation in the entorhinal cortex. However, a recent case report of a member of a Columbian family affected by dominantly inherited AD who managed to delay onset of disease for 3 decades after its expected onset, despite a heavy load of beta amyloid, shows that control of tau dispersion can be achieved [58]. In the absence of amyloid beta a condition called primary age-related tauopathy (PART) can arise in the elderly in which NFT are present but confined to the medial temporal lobe cortex in the absence of dementia [59]. Ultimately elimination of plaques at an early stage of their formation may well be valuable, just as avoidance of the formation of lipid streaks may benefit prevention of CVD, but I believe more leverage would be gained at the present time by aiming to prevent the spread of tau pathology in AD. 


\section{Acknowledgments}

This article is based on knowledge I have derived from a longstanding investigation as part of the Oxford Project to Investigate Memory and Ageing (OPTIMA) whose participants have enabled much useful research to be carried out.

\section{Author Contributions}

Margaret M Esiri did all the work.

\section{Funding}

In the recent past I have received funding from the UK National Institute for Health Research via the Oxford Biomedical Research Centre.

\section{Competing Interests}

I am a founder of Cytox Group and offer advice to the company Neurobio.

\section{References}

1. Cummings J, Lee G, Ritter A, Zhong K. Alzheimer's disease drug development pipeline: 2018. Alzheimers Dement. 2018; 4: 195-214.

2. Hardy JA, Higgins GA. Alzheimer's disease: The amyloid cascade hypothesis. Science. 1992; 256: 184-186.

3. De Strooper B, Karran E. The cellular phase of Alzheimer's disease. Cell. 2016; 164: 603-615.

4. Wilcock G, Esiri M. Plaques, tangles and dementia: A quantitative study. J Neurol Sci. 1982; 56: 343-356.

5. Tomlinson BE, Blessed G, Roth M. Observations on the brains of demented old people. J Neurol Sci. 1970; 11: 205-242.

6. Nagy Z, Esiri M, Jobst K, Morris J, King E-F, McDonald B, et al. Relative roles of plaques and tangles in the dementia of Alzheimer's disease: Correlations using three sets of neuropathological criteria. Dement Geriatr Cogn Disord. 1995; 6: 21-31.

7. Price JL, Morris JC. Tangles and plaques in nondemented aging and "preclinical" Alzheimer's disease. Ann Neurol. 1999; 45: 358-368.

8. Giannakopoulos $P$, Herrmann F, Bussière T, Bouras C, Kövari E, Perl D, et al. Tangle and neuron numbers, but not amyloid load, predict cognitive status in Alzheimer's disease. Neurology. 2003; 60: 1495-1500.

9. Knopman DS, Parisi JE, Salviati A, Floriach-Robert M, Boeve BF, Ivnik RJ, et al. Neuropathology of cognitively normal elderly. J Neuropathol Exp Neurol. 2003; 62: 1087-1095.

10. Savva GM, Wharton SB, Ince PG, Forster G, Matthews FE, Brayne C. Age, neuropathology, and dementia. N Engl J Med. 2009; 360: 2302-2309.

11. Bennett DA, Schneider JA, Wilson RS, Bienias JL, Arnold SE. Neurofibrillary tangles mediate the association of amyloid load with clinical Alzheimer disease and level of cognitive function. Arch Neurol. 2004; 61: 378-384. 
12. Nelson PT, Alafuzoff I, Bigio EH, Bouras C, Braak H, Cairns NJ, et al. Correlation of Alzheimer disease neuropathologic changes with cognitive status: A review of the literature. J Neuropathol Exp Neurol. 2012; 71: 362-381.

13. Berenson GS, Srinivasan SR, Bao W, Newman WP, Tracy RE, Wattigney WA. Association between multiple cardiovascular risk factors and atherosclerosis in children and young adults. N Engl J Med. 1998; 338: 1650-1656.

14. Rai V, Agrawal DK. The role of damage-and pathogen-associated molecular patterns in inflammation-mediated vulnerability of atherosclerotic plaques. Can J Physiol Pharmacol. 2017; 95: 1245-1253.

15. Bartsch T, Wulff P. The hippocampus in aging and disease: From plasticity to vulnerability. Elsevier; 2015.

16. Pearson RC, Esiri M, Hiorns R, Wilcock G, Powell T. Anatomical correlates of the distribution of the pathological changes in the neocortex in Alzheimer disease. Proc Natl Acad Sci. 1985; 82: 4531-4534.

17. Braak H, Braak E. Neuropathological stageing of Alzheimer-related changes. Acta Neuropathol. 1991; 82: 239-259.

18. Braak H, Del Tredici K. Spreading of tau pathology in sporadic Alzheimer's disease along cortico-cortical top-down connections. Cereb Cortex. 2018; 28: 3372-3384.

19. Walker LC, Jucker M. Neurodegenerative diseases: Expanding the prion concept. Annu Rev Neurosci. 2015; 38: 87-103.

20. Jackson WS. Selective vulnerability to neurodegenerative disease: The curious case of Prion Protein. Dis Model Mech. 2014; 7: 21-29.

21. Clavaguera F, Bolmont T, Crowther RA, Abramowski D, Frank S, Probst A, et al. Transmission and spreading of tauopathy in transgenic mouse brain. Nat Cell Biol. 2009; 11: 909-913.

22. Liu L, Drouet V, Wu JW, Witter MP, Small SA, Clelland C, et al. Trans-synaptic spread of tau pathology in vivo. PloS One. 2012; 7: e31302.

23. Meyer-Luehmann $M$, Friesen $M$. Ab seeding as a tool to study cerebral amyloidosis and associated pathology. Front Mol Neurosci. 2019; 12: 233.

24. Takeda S, Wegmann S, Cho H, DeVos SL, Commins C, Roe AD, et al. Neuronal uptake and propagation of a rare phosphorylated high-molecular-weight tau derived from Alzheimer's disease brain. Nat Commun. 2015; 6: 1-15.

25. Alonso AdC, Zaidi T, Novak M, Grundke-lqbal I, Iqbal K. Hyperphosphorylation induces selfassembly of $\tau$ into tangles of paired helical filaments/straight filaments. Proc Natl Acad Sci. 2001; 98: 6923-6928.

26. Wang JZ, Grundke-Iqbal I, Iqbal K. Kinases and phosphatases and tau sites involved in Alzheimer neurofibrillary degeneration. Eur J Neurosci. 2007; 25: 59-68.

27. He Z, Guo JL, McBride JD, Narasimhan S, Kim H, Changolkar L, et al. Amyloid- $\beta$ plaques enhance Alzheimer's brain tau-seeded pathologies by facilitating neuritic plaque tau aggregation. Nat Med. 2018; 24: 29-38.

28. Gomes LA, Hipp SA, Upadhaya AR, Balakrishnan K, Ospitalieri S, al KMe. Abeta-induced acceleration of Alzheimer-related pathology spreading and its association with prion protein. Acta Neuroathol. 2019; 138: 913-941. 
29. Hayden EY, Putman J, Nunez S, Shin WS, Oberoi M, Charreton M, et al. Ischemic axonal injury up-regulates MARK4 in cortical neurons and primes tau phosphorylation and aggregation. Acta Neuropathol Commun. 2019; 7: 1-12.

30. Uddin MS, Kabir MT, Al Mamun A, Abdel-Daim MM, Barreto GE, Ashraf GM. APOE and Alzheimer's disease: Evidence mounts that targeting APOE4 may combat Alzheimer's pathogenesis. Mol Neurobiol. 2019; 56: 2450-2465.

31. Li T, Zhu J. Entanglement of CCR5 and Alzheimer's disease. Front Aging Neurosci. 2019; 11: 209.

32. López-González I, Schlüter A, Aso E, Garcia-Esparcia P, Ansoleaga B, Llorens F, et al. Neuroinflammatory signals in Alzheimer disease and APP/PS1 transgenic mice: Correlations with plaques, tangles, and oligomeric species. J Neuropathol Exp Neurol. 2015; 74: 319-344.

33. Clark IA, Alleva LM, Vissel B. The roles of TNF in brain dysfunction and disease. Pharmacol Ther. 2010; 128: 519-548.

34. Shen LL, Li WW, Xu YL, Gao SH, Xu MY, Bu XL, et al. Neurotrophin receptor p75 mediates amyloid $\beta$-induced tau pathology. Neurobiol Dis. 2019; 132: 104567.

35. Park S, Lee JH, Jeon JH, Lee MJ. Degradation or aggregation: The ramifications of posttranslational modifications on tau. BMB Rep. 2018; 51: 265-273.

36. Chatterjee S, Ambegaokar S, Jackson GR, Mudher A. Insulin-mediated changes in tau hyperphosphorylation and autophagy in a Drosophila model of tauopathy and neuroblastoma cells. Front Neurosci. 2019; 13: 801.

37. Mudher A, Colin M, Dujardin S, Medina M, Dewachter I, Naini SMA, et al. What is the evidence that tau pathology spreads through prion-like propagation? Acta Neuropathol Commun. 2017; 5: 99.

38. Asai H, Ikezu S, Tsunoda S, Medalla M, Luebke J, Haydar T, et al. Depletion of microglia and inhibition of exosome synthesis halt tau propagation. Nat Neurosci. 2015; 18: 1584.

39. Hopp SC, Lin Y, Oakley D, Roe AD, DeVos SL, Hanlon D, et al. The role of microglia in processing and spreading of bioactive tau seeds in Alzheimer's disease. J Neuroinflammation. 2018; 15: 115.

40. Sosna J, Philipp S, Albay R, Reyes-Ruiz JM, Baglietto-Vargas D, LaFerla FM, et al. Early longterm administration of the CSF1R inhibitor PLX3397 ablates microglia and reduces accumulation of intraneuronal amyloid, neuritic plaque deposition and pre-fibrillar oligomers in 5XFAD mouse model of Alzheimer's disease. Mol Neurodegener. 2018; 13: 11.

41. Španić $E$, Langer Horvat L, Hof PR, Simic G. Role of microglial cells in Alzheimer's disease tau propagation. Front Aging Neurosci. 2019; 11: 271.

42. Walsh DM, Selkoe DJ. A critical appraisal of the pathogenic protein spread hypothesis of neurodegeneration. Nat Rev Neurosci. 2016; 17: 251-260.

43. Huppert FA, Brayne C, O'Connor DW. Dementia and normal aging. Cambridge University Press; 1994.

44. Alonso AdC, Zaidi T, Grundke-lqbal I, Iqbal K. Role of abnormally phosphorylated tau in the breakdown of microtubules in Alzheimer disease. Proc Natl Acad Sci. 1994; 91: 5562-5566.

45. Alonso AdC, Grundke-lqbal I, Iqbal K. Alzheimer's disease hyperphosphorylated tau sequesters normal tau into tangles of filaments and disassembles microtubules. Nat Med. 1996; 2: 783-787. 
46. Alonso AdC, Li B, Grundke-Iqbal I, Iqbal K. Polymerization of hyperphosphorylated tau into filaments eliminates its inhibitory activity. Proc Natl Acad Sci. 2006; 103: 8864-8869.

47. Long JM, DM H. Alzheimer disease: An update on pathology and treatment strategies. Cell. 2019; 179: 312-319.

48. Cummings J, Blennow K, Johnson K, Keeley M, Bateman R, Molinuevo J, et al. Anti-tau trials for Alzheimer's disease: A report from the EU/US/CTAD Task Force. J Prev Alzheimers Dis. 2019; 6: 157-163.

49. Nobuhara CK, DeVos SL, Commins C, Wegmann S, Moore BD, Roe AD, et al. Tau antibody targeting pathological species blocks neuronal uptake and interneuron propagation of tau in vitro. Am J Pathol. 2017; 187: 1399-1412.

50. Yanamandra K, Kfoury N, Jiang H, Mahan TE, Ma S, Maloney SE, et al. Anti-tau antibodies that block tau aggregate seeding in vitro markedly decrease pathology and improve cognition in vivo. Neuron. 2013; 80: 402-414.

51. Collin L, Bohrmann B, Göpfert U, Oroszlan-Szovik K, Ozmen L, Grüninger F. Neuronal uptake of tau/pS422 antibody and reduced progression of tau pathology in a mouse model of Alzheimer's disease. Brain. 2014; 137: 2834-2846.

52. Shamir DB, Rosenqvist N, Rasool S, Pedersen JT, Sigurdsson EM. Internalization of tau antibody and pathological tau protein detected with a flow cytometry multiplexing approach. Alzheimers Dement. 2016; 12: 1098-1107.

53. Gallardo G, Wong CH, Ricardez SM, Mann CN, Lin KH, Leyns CE, et al. Targeting tauopathy with engineered tau-degrading intrabodies. Mol neurodegener. 2019; 14: 38.

54. Qiu C, Fratiglioni L. Aging without dementia is achievable: Current evidence from epidemiological research. J Alzheimers Dis. 2018; 62: 933-942.

55. Pontecorvo MJ, Devous MD, Kennedy I, Navitsky M, Lu M, Galante N, et al. A multicentre longitudinal study of flortaucipir (18F) in normal ageing, mild cognitive impairment and Alzheimer's disease dementia. Brain. 2019; 142: 1723-1735.

56. Wang L, Benzinger TL, Su Y, Christensen J, Friedrichsen K, Aldea P, et al. Evaluation of tau imaging in staging Alzheimer disease and revealing interactions between $\beta$-amyloid and tauopathy. JAMA Neurol. 2016; 73: 1070-1077.

57. Dai CL, Tung YC, Liu F, Gong CX, Iqbal K. Tau passive immunization inhibits not only tau but also Abeta pathology. Alzheimers Res Ther. 2017; 9: 1.

58. Arboleda-Velasquez JF, Lopera F, O'Hare M, Delgado-Tirado S, Marino C, Chmielewska N, et al. Resistance to autosomal dominant Alzheimer's disease in an APOE3 Christchurch homozygote: A case report. Nat Med. 2019; 25: 1680-1683.

59. Crary JF, Trojanowski JQ, Schneider JA, Abisambra JF, Abner EL, Alafuzoff I, et al. Primary agerelated tauopathy (PART): A common pathology associated with human aging. Acta Neuropathol. 2014; 128: 755-766. 


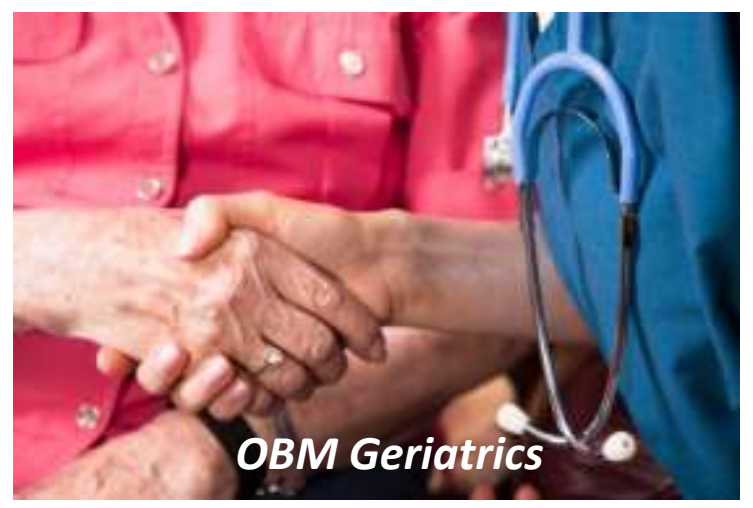

Enjoy $O B M$ Geriatrics by:

1. Submitting a manuscript

2. Joining in volunteer reviewer bank

3. Joining Editorial Board

4. Guest editing a special issue

For more details, please visit: http://www.lidsen.com/journals/geriatrics 